\title{
Thermal Degradation Kinetics of Para-Substituted Poly (styrene Peroxide)s in Solution
}

\author{
Priyadarsi De, ${ }^{1}$ Sujay Chattopadhyay, ${ }^{2}$ Giridhar Madras, ${ }^{2}$ D. N. Sathyanarayana ${ }^{2}$ \\ ${ }^{1}$ Department of Inorganic and Physical Chemistry, Indian Institute of Science, Bangalore-560012, India \\ ${ }^{2}$ Department of Chemical Engineering, Indian Institute of Science, Bangalore-560012, India
}

Received 4 June 2001; accepted 8 January 2002

\begin{abstract}
The thermal degradation of three polymeric peroxides of styrene monomers with substituents in the para position was studied at various temperatures $(65,75,85$, and $\left.95^{\circ} \mathrm{C}\right)$. A continuous distribution model was used to evaluate the rate coefficients for the random-chain and chain-end scission degradation from the evolution of molecular weight distributions with time. The activation energy determined from the temperature dependence of the rate coefficients was in the range $18-22 \mathrm{kcal} \mathrm{mol}^{-1}$. This result suggests that
\end{abstract}

the thermal degradation of polyperoxide is controlled by the dissociation of the $\mathrm{O}-\mathrm{O}$ bonds in the polymer backbone. The thermal stability for poly ( $p$-methylstyrene peroxide) lies in between that of poly( $p$-tert-butylstyrene peroxide) (highest) and $\operatorname{poly}(p$-bromostyrene peroxide) (lowest). (c) 2002 Wiley Periodicals, Inc. J Appl Polym Sci 86: 957-961, 2002

Key words: polyperoxide; thermal degradation; molecular weight distributions; activation energy

\section{INTRODUCTION}

Research on vinyl polyperoxides, which are a narrow but important class of polymers, is witnessing a renaissance because of the unique physicochemical behavior of these chemicals. ${ }^{1}$ The polyperoxides, which are alternating copolymers of the vinyl monomers and oxygen, find importance as polymeric thermal-, photo-, and base-catalyzed initiators for vinyl monomers to synthesize homopolymers, block, and comblike copolymers. ${ }^{2}$ Most polymers degrade endothermally, whereas vinyl polyperoxides are an unique class of polymers that pyrolyze exothermally. ${ }^{3}$ Further, their unique properties, such as auto-pyrolyzability and auto-combustibility, make them potential candidates for specialized fuels. ${ }^{3}$

The investigation of the decomposition kinetics of the initiator is essential to understand the kinetics of vinyl polymerization initiated by vinyl polyperoxides. Though the decomposition of common initiators, such as benzoyl peroxide, 2,2'-azobis(isobutyronitrile) (AIBN), etc., have been well studied, ${ }^{4}$ no studies have been made on the chemical reactivity of polyperoxides. This is the first systematic study of the thermal degradation in solution of three polymeric peroxides that can be used as initiators for vinyl polymerization. The polyperoxides are poly( $p$-methylstyrene peroxide) (PPMSP), poly( $p$-bromostyrene peroxide) (PP-

Correspondence to: G. Madras (giridhar@chemeng.iisc. ernet.in).

Journal of Applied Polymer Science, Vol. 86, 957-961 (2002) (C) 2002 Wiley Periodicals, Inc.
$\mathrm{BrSP})$ and poly(p-tert-butylstyrene peroxide) (PPT$\mathrm{BSP})$, and each has have the following general structure:<smiles>[R]OOC(CC)c1ccc([R])cc1</smiles>

where $\mathrm{R}$ is $\mathrm{CH}_{3}, \mathrm{Br}$, and $\mathrm{C}\left(\mathrm{CH}_{3}\right)_{3}$ for PPMSP, PPBrSP, and PPTBSP, respectively. The synthesis and characterization of these polymers have been recently reported. $^{5}$

\section{EXPERIMENTAL}

The monomers were freed from inhibitor by distillation at reduced pressure. Other chemicals, such as azobisisobutyronitrile (AIBN), chloroform etc., were purified by distillation and filtration.

All polyperoxides were prepared by oxidative polymerization as reported elsewhere ${ }^{5}$ and characterized by proton and carbon-13 nuclear magnetic resonance spectroscopy $\left({ }^{1} \mathrm{H}\right.$ and ${ }^{13} \mathrm{C}$ NMR, respectively) recorded on a Bruker AC-F $200 \mathrm{MHz}$ spectrometer in $\mathrm{CDCl}_{3}$ and $\mathrm{CH}_{2} \mathrm{Cl}_{2}\left(\mathrm{D}_{2} \mathrm{O}\right.$ external lock), respectively.

Thermal decomposition of polyperoxides was studied in toluene at $65,75,85$, and $95^{\circ} \mathrm{C}$. First, $100 \mathrm{~mL}$ of the polymer solution $\left(2.5 \mathrm{~g} \mathrm{~L}^{-1}\right)$ was placed in a 250-mL two-necked round-bottomed flask that was fitted with a reflux condenser to avoid loss of any volatile products. The flask was kept in an oil bath, and the solution was continuously stirred while the 


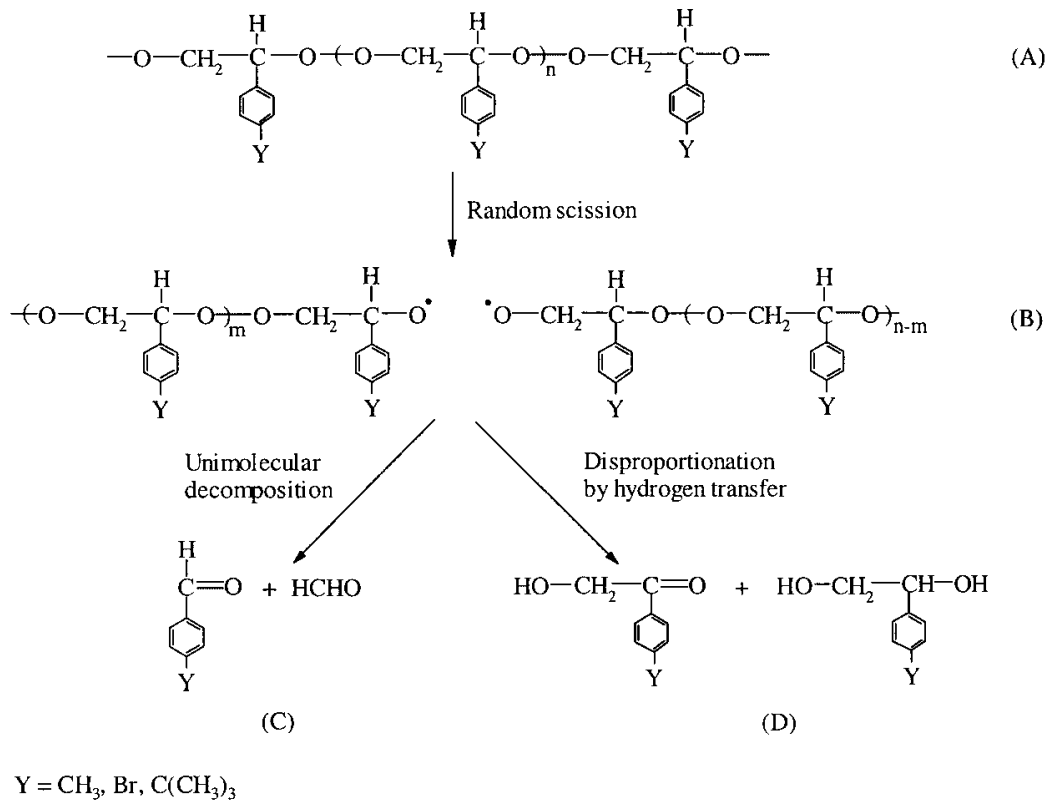

Scheme 1

temperature was controlled within $\pm 0.5^{\circ} \mathrm{C}$ throughout the degradation. Samples of $1 \mathrm{~mL}$ were periodically taken and analyzed by gel permeation chromatography (GPC) according to a procedure described elsewhere. ${ }^{6}$ Based on triplicate experiments, the standard deviation in the rate coefficient was $<5 \%$.

\section{DISCUSSION}

\section{Reaction model}

Vinyl polyperoxides usually degrade exothermally by cleavage at weak peroxy links, forming macroalkoxy radicals that undergo two types of reactions: unimolecular decomposition and disproportionation (see Scheme 1). In the degradation of poly(styrene peroxide) (PSP), these are competing processes. ${ }^{2}$ The main products of the disproportionation pathway are $\alpha$-hydroxy acetophenone, phenylglycol, and small quantities of phenyl glyoxal. In the unimolecular decomposition of PSP, which is a chain unzipping process, the macroalkoxy radicals undergo scission at the $\beta$-bond to the radical center, forming the carbonyl compounds benzaldehyde and formaldehyde.

The formation of products from disproportionation via hydrogen transfer is negligible $(<8 \%)$. This result was supported by the fact that no products are detected in the ${ }^{13} \mathrm{C}$ NMR spectra of the mixture that results from heating PPMSP at $95^{\circ} \mathrm{C}$ for $10 \mathrm{~h}$. The polyperoxides PPMSP, PPBrSP, and PPTBSP degrade to $p$-methylbenzaldehyde, $p$-bromobenzaldehyde, and $p$-tert-butylbenzaldehyde, respectively, and formaldehyde.
The ${ }^{1} \mathrm{H}$ and ${ }^{13} \mathrm{C}$ NMR spectra reveal the formation of alternating copolymer of the vinyl monomer and oxygen. The starting number average molecular weights of PPMSP, PPBrSP, and PPTBSP, as determined by GPC, are 2700, 2200, and 2700, respectively, with polydispersities of 1.3, 1.4, and 1.3, respectively. The polyperoxides have low ${ }^{2}$ molecular weight because of various chain transfer reactions occurring during oxygen copolymerization.

\section{Kinetic model}

The degradation of long chain molecules can be well understood by the continuous distribution models. ${ }^{7}$ Let $\mathrm{P}(x), \mathrm{R}(x)$, and $\mathrm{R}_{\mathrm{e}}(x)$, represent the polymer,

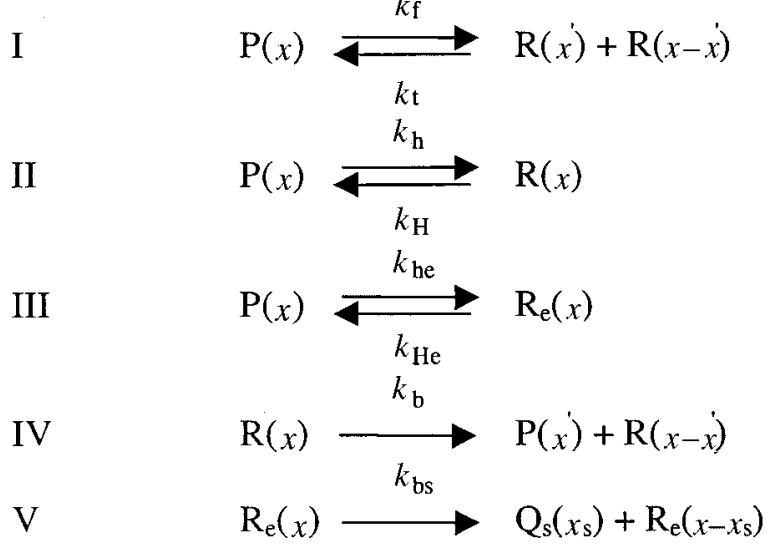

Scheme 2 


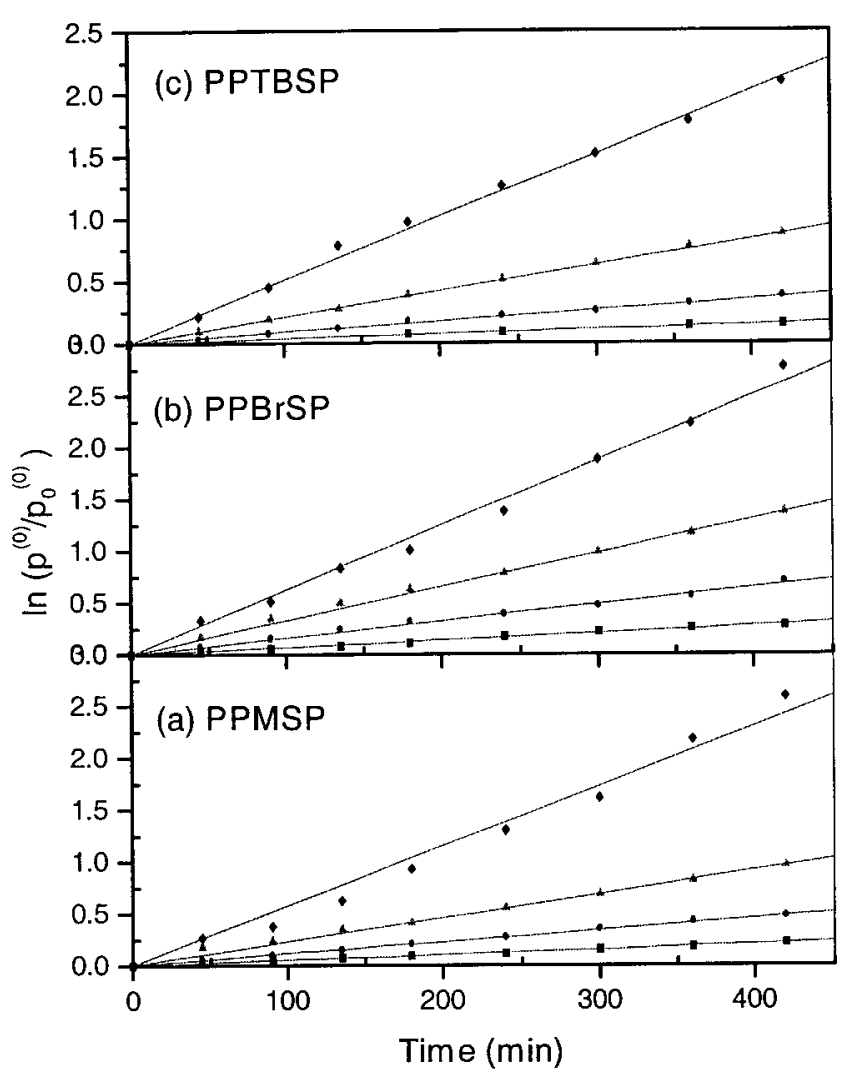

Figure 1 Plot of $\ln \left(\mathrm{p}^{(0)} / \mathrm{p}_{0}{ }^{(0)}\right)$ versus time to determine random scission rate coefficient $\left(k_{1}\right)$ at $65(\boldsymbol{\square}), 75(\mathbf{O}), 85(\mathbf{\Delta})$, and $95(\boldsymbol{\nabla}){ }^{\circ} \mathrm{C}$ for (a) PPMSP, (b) PPBrSP, and (c) PPTBSP, respectively.

radical, and end radicals of molecular weight $x$. For the polymers studied, both the specific products occur at the same step, and thus $Q_{\mathrm{s}}$ represents both the specific products. The degradation can be expressed in a generalized form as shown in steps I-V in Scheme 2.

Step I in the mechanism shown in scheme 2 represents the formation of B from A. Steps II and III are due to the formation of D from B. Step IV represents the formation of A and a radical from B. Step V signifies the formation of unimolecular decomposition products $C$ and a radical from $B$. The polymer molecules decompose into radicals $\left(\mathrm{R}, \mathrm{R}_{\mathrm{e}}\right)$ and these radicals then give rise to smaller radicals, polymer, and specific products.

Scheme 2 includes major elementary steps of the Rice-Herzfeld mechanism as discussed by Aris and Gavalas $^{8}$ and Nigam et al. ${ }^{9}$ This mechanism is similar to the degradation of polystyrene-allyl alcohol in solution, ${ }^{10}$ where both random and specific chain scissions were observed. It is reasonable to assume that steps IV and V are irreversible because of the negligible probability of polymerization at the temperatures of study. The population balance equations for the reacting species are ${ }^{7}$

$$
\begin{aligned}
& \frac{\partial \mathrm{p}(x, t)}{\partial t} \\
& =-k_{\mathrm{f}} \mathrm{p}(x, t)+k_{t} \int_{0}^{x} \mathrm{r}\left(x^{\prime}\right) \mathrm{r}\left(x-x^{\prime}\right) \mathrm{d} x^{\prime}+k_{\mathrm{H}} \mathrm{r}(x)-k_{\mathrm{h}} \mathrm{p}(x, t) \\
& -k_{\mathrm{he}} \mathrm{p}(x, t)+k_{\mathrm{He}} \mathrm{r}_{\mathrm{e}}(x)+k_{\mathrm{b}} \int_{\mathrm{r}}^{\infty}\left(x^{\prime}\right) \Omega\left(x, x^{\prime}\right) \mathrm{d} x^{\prime} \\
& \frac{\partial \mathrm{r}(x, t)}{\partial t} \\
& =2 k_{\mathrm{f}} \int_{x}^{\infty} \mathrm{p}\left(x^{\prime}\right) \Omega\left(x, x^{\prime}\right) \mathrm{d} x^{\prime}-2 k_{t} \mathrm{r}(x) \int_{0}^{\infty} \mathrm{r}\left(x^{\prime}\right) \mathrm{d} x^{\prime}+k_{\mathrm{h}} \mathrm{p}(x) \\
& -k_{\mathrm{H}} \mathrm{r}(x)+k_{\mathrm{b}}^{\infty} \mathrm{r}\left(x^{\prime}\right) \Omega\left(x, x^{\prime}\right) \mathrm{d} x^{\prime}-k_{\mathrm{b}} \mathrm{r}(x)
\end{aligned}
$$

$\frac{\partial \mathrm{r}_{\mathrm{e}}(x, t)}{\partial t}=k_{\mathrm{he}} \mathrm{p}(x)-k_{\mathrm{He}} \mathrm{r}_{\mathrm{e}}(x)$

$$
+k_{\mathrm{bs}} \int_{x}^{\infty} \mathrm{r}_{\mathrm{e}}\left(x^{\prime}\right) \delta\left[x-\left(x^{\prime}-x_{\mathrm{s}}\right)\right] \mathrm{d} x^{\prime}-k_{\mathrm{bs}} \mathrm{r}_{\mathrm{e}}(x)
$$

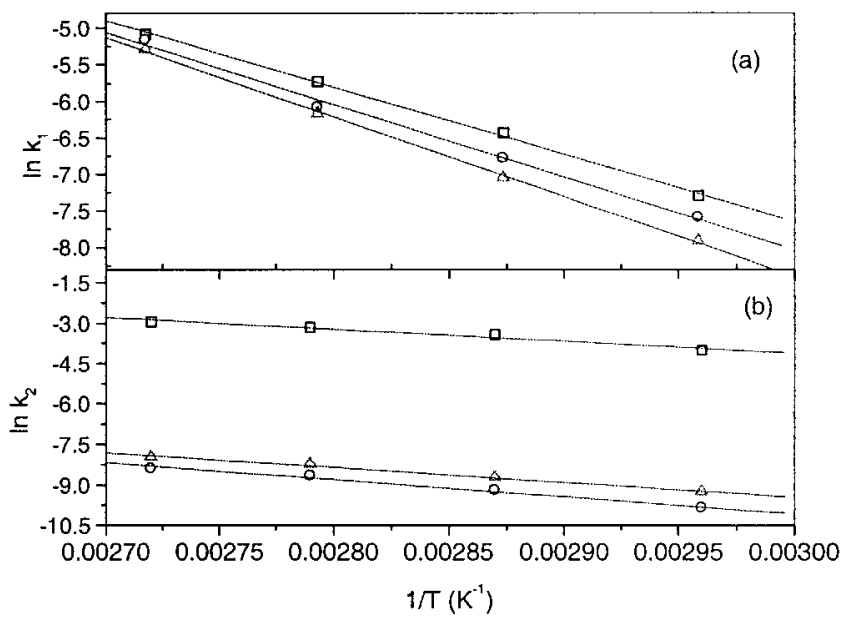

Figure 2 Arrhenius plot to determine the activation energy for (a) random chain scission and (b) specific chain scission for $\operatorname{PPBrSP}(\square), \operatorname{PPMSP}(\bigcirc)$, and $\operatorname{PPTBSP}(\triangle)$. 


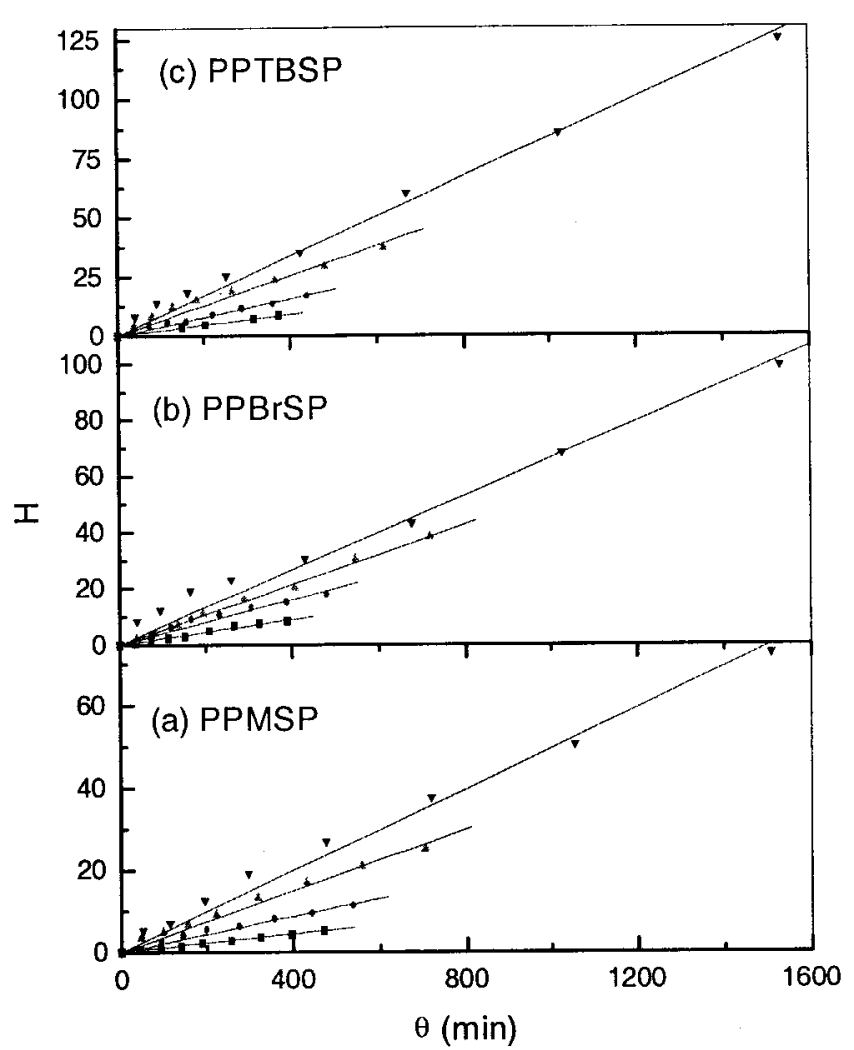

Figure 3 Plot of $H$ versus $\theta$ determine specific chain scission rate coefficient $\left(k_{2}\right)$ at $65(\boldsymbol{\square}), 75(\mathbf{O}), 85(\mathbf{\Delta})$, and $95(\boldsymbol{\nabla})$ ${ }^{\circ} \mathrm{C}$ for (a) PPMSP, (b) PPBrSP, and (c) PPTBSP, respectively.

$$
\frac{\partial \mathrm{q}_{\mathrm{s}}(x, t)}{\partial t}=k_{\mathrm{bs}} \int_{x}^{\infty} \mathrm{r}_{\mathrm{e}}\left(x^{\prime}\right) \delta\left(x^{\prime}-x_{\mathrm{s}}\right) \mathrm{d} x^{\prime}
$$

where, $p(x, t)$ and $r(x, t)$ represent the molar concentration of the polymer and the radical, respectively, and $\Omega\left(x, x^{\prime}\right)$ denotes the stoichiometric kernel and is equal to $1 / x^{\prime}$ for random chain scission. ${ }^{10}$ All the reactions are considered to be first order with respect to the reacting components. Due to low conversion, it is reasonable to assume that the rate coefficients are independent of the polymer chain length. ${ }^{10}$ The initial conditions are $\mathrm{p}(x, t=0)=\mathrm{p}_{0}^{(0)}$ and $\mathrm{r}(x, t=0)=0, \mathrm{r}_{\mathrm{e}}(x, t$ $=0)=0$, and $\mathrm{q}_{\mathrm{s}}(x, t=0)=0$. Applying the moment operation, ${ }^{7}$ defined as $\mathrm{p}^{(n)}(t)=\int_{0}^{\infty} x^{(n)} \mathrm{p}(x, t) \mathrm{d} x$, on the integro-differential eqs. $1-4$, and applying two simplifying assumptions of long-chain approximation (the rate of initiation and termination are assumed to be negligible) and quasi-steady-state approximation (QSSA, rate of change of radical concentration is zero), the time variation of the molar concentration of the polymer, $\mathrm{p}^{(0)}$, is $^{7}$

$$
\mathrm{p}^{(0)}=\mathrm{p}_{0}^{(0)} e^{k_{1} t}
$$

where $k_{1}$ is equal to $k_{\mathrm{b}} k_{\mathrm{h}} / k_{\mathrm{H}}$.

\section{Determination of specific scission rate coefficient}

The time dependent molar concentration of the specific products can be obtained as 7,10

$$
\mathrm{q}_{\mathrm{s}}^{(1)}(t)=k_{2} \mathrm{x}_{\mathrm{s}} \mathrm{p}_{0}^{(0)} \frac{\left(e^{k_{1} t}-1\right)}{k_{1}}
$$

where $k_{2}\left(=k_{\mathrm{b}} k_{\text {he }} / k_{\mathrm{He}}\right)$. Thus, a plot of $H\left(=\mathrm{q}_{\mathrm{s}}^{(1)} / x_{\mathrm{s}} \mathrm{p}_{0}^{(0)}\right)$ versus $\theta\left(=\left(e^{k_{1} t}-1\right) / k_{1}\right)$ would yield the slope corresponding to the specific degradation rate coefficient, $k_{2}$.

The molar concentration of the polymer, $\mathrm{p}^{(0)}$, can be determined from the time evolution of the MWD. Though the specific products formed were not identifiable by GPC (because of the merging of the peaks due to toluene and specific product), the amount of specific products can be calculated by subtracting the mass of random scission products (determined by GPC) from the total initial mass.

The plots of $\ln \left(\mathrm{p}^{(0)} / \mathrm{p}_{0}^{(0)}\right)$ with time for PPMSP, PP$\mathrm{BrSP}$, and PPTBSP, with slope yielding the rate coefficient, $k_{1}$, for the thermal degradation at various temperatures are shown in Figure 1. The values of the degradation rate coefficient for PPMSP, PPBrSP, and PPTBSP, at $75^{\circ} \mathrm{C}$ are $1.13 \times 10^{-3} 1.60 \times 10^{-3}$, and 0.87 $\times 10^{-3} \mathrm{~min}^{-1}$, respectively. The differences in the rate coefficients of thermal decomposition of the three polyperoxides could be attributed to the differences in the structures of the polyperoxides and the radicals produced during the degradation.

The Arrhenius plot of the rate coefficients for random scission is shown in Figure 2a. The energies of activation $\left(E_{\text {act }}\right)$ for the $\mathrm{O}-\mathrm{O}$ bond cleavage determined from the slope were 19.7, 18.2, and $21.7 \mathrm{kcal}$ $\mathrm{mol}^{-1}$ for PPMSP, PPBrSP, and PPTBSP, respectively. The activation energies for thermal degradation in the solid state were $39.0,36.8$, and $43.7 \mathrm{kcal} \mathrm{mol}^{-1}$ for PPMSP, PPBrSP, and PPTBSP, respectively. ${ }^{5}$ The activation energies for thermal degradation in solution are $45-50 \%$ lower than those in the solid state. ${ }^{5}$ The low activation energies for thermal degradation in solution suggests that uniform heat transfer to the polymer molecules favor decomposition in solution compared with the solid state. ${ }^{10}$ The relative stability of the polyperoxides can be compared from the activation energies for thermal degradation data. Both the $E_{\text {act }}$ values and random chain degradation rate coefficients follow the trend PPTBSE $>$ PPMSP $>$ PPBrSP. The electron-withdrawing group $(\mathrm{Br})$ stabilizes the macroradicals form in chain scission. Therefore, the corresponding substituted poly(styrene peroxide)s are less stable than unsubstituted polymer. In contrast, electron-donating groups $\left[\mathrm{CH}_{3}\right.$ and $\left.\mathrm{C}\left(\mathrm{CH}_{3}\right)_{3}\right]$ destabi- 
lize these macroradicals, and the corresponding polymers are more stable. The order of stability determined from the activation energies is the same as that determined from the rate coefficients.

The determination of specific scission rate coefficients for PPMSP, PPBrSP, and PPTBSP, respectively, are shown in Figure 3. The energies of activation for the specific products obtained from the Arrhenius plot (Figure $2 \mathrm{~b}$ ) are 11.8, 10.2, and $10.8 \mathrm{kcal} \mathrm{mol}^{-1}$ for PPMSP, PPBrSP, and PPTBSP, respectively. The activation energies for specific products are usually in the range $6-12 \mathrm{kcal} \mathrm{mol}^{-1}$.,10

\section{References}

1. De, P.; Sathyanarayana, D. N.; Murthy, S. P.; Sridhar, S. Polymer 2001, 42, 8587.

2. Mukundan, T.; Kishore, K. Prog Polym Sci 1990, 15, 475.

3. Kishore, K.; Mukundan, T. Nature 1986, 324, 130.

4. Odian, G. Principles of Polymerization, 3rd ed.; Wiley-Interscience: New York, 1991.

5. De, P.; Sathyanarayana, D. N. Macromol Chem Phys, submitted. 6. Madras, G.; Chattopadhyay, S. J Appl Polym Sci 2001, 81, 1996.

7. Kodera, Y.; McCoy, B. J. AIChE J 1997, 43, 3205.

8. Aris, R.; Gavalas, G. R. Phil Trans R Soc, London, 1966, A260, 351.

9. Nigam, A.; Fake, D. M.; Klein, T. M. AIChE J 1997, 43, 3205.

10. Wang, M.; Smith, J. M.; McCoy, B. J. AIChE J 1995, 41, 1521. 